\title{
Influence of landscape homogenization due to river damming on dragonfly (Odonata) community structuring in a subtropical forest in the southern Atlantic Forest
}

\author{
Breno R. Araujo ${ }^{1}$, Ângelo Parise Pinto ${ }^{1}$, and André A. Padial ${ }^{2}$ \\ ${ }^{1}$ Universidade Federal do Parana Departamento de Zoologia \\ ${ }^{2}$ Universidade Federal do Parana
}

September 27, 2021

\begin{abstract}
Human activities affect the structure, dynamics, and energy flow of aquatic ecosystems. River damming, a common anthropic impact in Brazil, changes solar incidence, water flow, and temperature of waterbodies, thereby affecting their fauna. Due to their high sensitivity to environmental changes, the Odonata may be indicators of these impacts. We sampled two ecologically distinct sites, (1) a quasi-pristine forested area; and (2) a nearby human-impacted reservoir landscape, to evaluate the effects of damming on odonate community structure. The species composition of quasi-pristine communities was more heterogeneous and differed almost completely (indicating high turnover) from that of the reservoir-area communities. The capacity of the reservoir to maintain local fauna was almost nil. The communities in the changed landscape had the highest local diversity, which is related to the high occurrence of widespread generalist South American species. We also tested two recently proposed bioindication ratio tools based on the abundance of high-level taxonomic categories; both effectively demonstrated the extent of the impacts of damming. The best performing ratios were Coenagrionidae/other Zygoptera richness ratio, Zygoptera/Anisoptera abundance ratio, and Libellulidae/other Anisoptera richness ratio. The reservoir landscape promotes biotic homogenization. However, the water supply system entails the preservation of part of the native habitat in its surrounding areas, consequently maintaining local biodiversity in quasi-pristine environments.
\end{abstract}

\section{Hosted file}

2021_Araujo_et_al_Manuscrit_Main_Doc_EcoHydrology_Submission_Revised.docx available at https://authorea.com/users/437043/articles/538958-influence-of-landscape-homogenizationdue-to-river-damming-on-dragonfly-odonata-community-structuring-in-a-subtropical-forestin-the-southern-atlantic-forest 